HeId onlinefrom UCL, Institute of Education, UK July $22-25,2021$
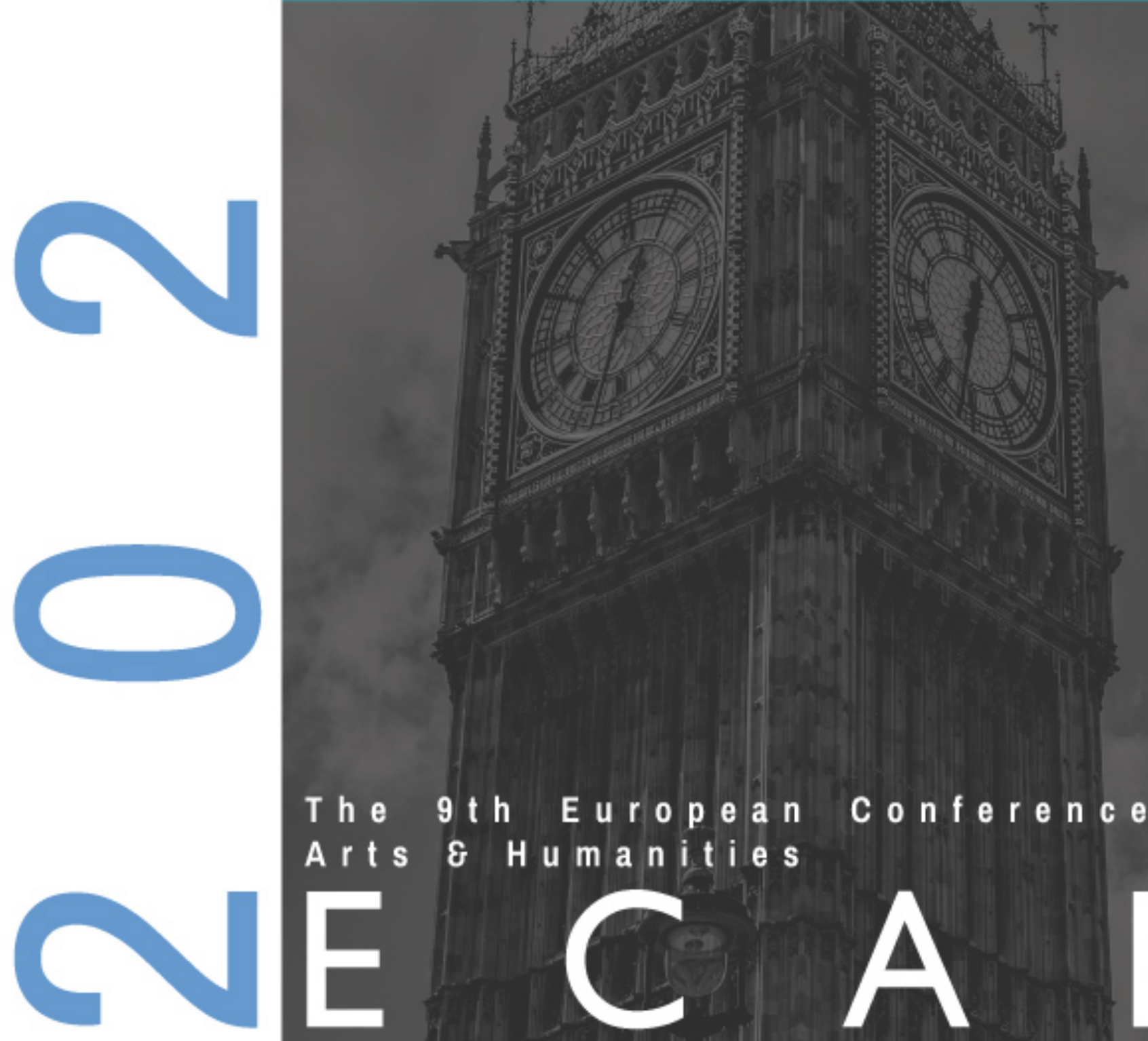

The 9 th European Conference on Arts $\&$ Humanities
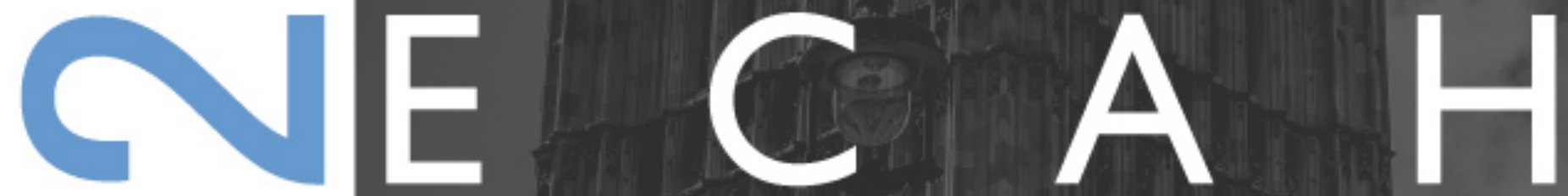

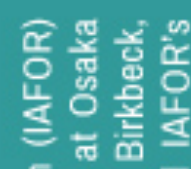

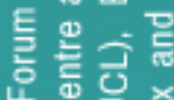

OFFICIAL CONFERENCE PROCEEDINGS

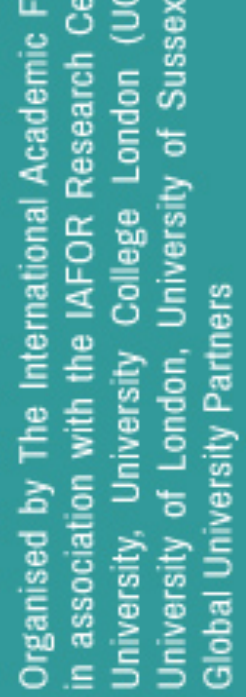

IS S N: $2188-1111$ 

"To Open Minds, To Educate Intelligence, To Inform Decisions"

The International Academic Forum provides new perspectives to the thought-leaders and decision-makers of today and tomorrow by offering constructive environments for dialogue and interchange at the intersections of nation, culture, and discipline. Headquartered in Nagoya, Japan, and registered as a Non-Profit Organization (一般社 団法人) , IAFOR is an independent think tank committed to the deeper understanding of contemporary geo-political transformation, particularly in the Asia Pacific Region.

\section{INTERNATIONAL \\ INTERCULTURAL \\ INTERDISCIPLINARY}

iafor 



\section{The Executive Council of the International Advisory Board}

\section{Mr Mitsumasa Aoyama}

Director, The Yufuku Gallery, Tokyo, Japan

\section{Lord Charles Bruce}

Lord Lieutenant of Fife

Chairman of the Patrons of the National Galleries of Scotland

Trustee of the Historic Scotland Foundation, UK

\section{Professor Donald E. Hall}

Herbert J. and Ann L. Siegel Dean

Lehigh University, USA

Former Jackson Distinguished Professor of English and Chair of the Department of English

\section{Professor Arthur Stockwin}

Founding Director of the Nissan Institute for Japanese Studies \& Emeritus Professor The University of Oxford UK

\section{Professor Chung-Ying Cheng}

Professor of Philosophy, University of Hawaili at Manoa, USA

Editor-in-Chief, The Journal of Chinese Philosophy

\section{Professor Steve Cornwell}

Professor of English and Interdisciplinary Studies, Osaka Jogakuin University, Osaka, Japan

Osaka Local Conference Chair

\section{Professor A. Robert Lee}

Former Professor of English at Nihon University, Tokyo from 1997 to 201 I, previously long taught at the University of Kent at Canterbury, UK

\section{Professor Dexter Da Silva}

Professor of Educational Psychology, Keisen University, Tokyo, Japan

\section{Professor Georges Depeyrot}

Professor and Director of Research \& Member of the Board of Trustees

French National Center for Scientific Research (CNRS) \& L'Ecole Normale Superieure, Paris, France

\section{Professor Johannes Moenius}

William R. and S. Sue Johnson Endowed Chair of Spatial Economic Analysis and Regional Planning The University of Redlands School of Business, USA

\section{Professor June Henton}

Dean, College of Human Sciences, Auburn University, USA

\section{Professor Michael Hudson}

President of The Institute for the Study of Long-Term Economic Trends (ISLET)

Distinguished Research Professor of Economics, The University of Missouri, Kansas City

\section{Professor Koichi Iwabuchi}

Professor of Media and Cultural Studies \& Director of the Monash Asia Institute, Monash University, Australia

\section{Professor Sue Jackson}

Professor of Lifelong Learning and Gender \& Pro-Vice Master of Teaching and Learning, Birkbeck, University of London, UK

\section{Professor Sir Geoffrey Lloyd}

Senior Scholar in Residence, The Needham Research Institute, Cambridge, UK

Fellow and Former Master, Darwin College, University of Cambridge

Fellow of the British Academy

Professor Keith Miller

Orthwein Endowed Professor for Lifelong Learning in the Science, University of Missouri-St.Louis, USA

\section{Professor Kuniko Miyanaga}

Director, Human Potential Institute, Japan

Fellow, Reischauer Institute, Harvard University, USA

\section{Professor Dennis Mclnerney}

Chair Professor of Educational Psychology and CoDirector of the Assessment Research Centre The Hong Kong Institute of Education, Hong Kong SAR

\section{Professor Brian Daizen Victoria}

Professor of English

Fellow of the Oxford Centre for Buddhist Studies

\section{Professor Michiko Nakano}

Professor of English \& Director of the Distance Learning Center, Waseda University, Tokyo, Japan

Professor Thomas Brian Mooney

Professor of Philosophy

Head of School of Creative Arts and Humanities Professor of Philosophy and Head of School of Creative Arts and Humanities, Charles Darwin University, Australia

\section{Professor Baden Offord}

Professor of Cultural Studies and Human Rights \& CoDirector of the Centre for Peace and Social Justice Southern Cross University, Australia

Professor Frank S. Ravitch

Professor of Law \& Walter H. Stowers Chair in Law and Religion, Michigan State University College of Law

\section{Professor Richard Roth}

Senior Associate Dean, Medill School of Journalism,

Northwestern University, Qatar

Professor Monty P. Satiadarma

Clinical Psychologist and Lecturer in Psychology \&

Former Dean of the Department of Psychology and Rector of the University, Tarumanugara University, Indonesia

\section{Mr Mohamed Salaheen}

Director, The United Nations World Food Programme, Japan \& Korea

\section{Mr Lowell Sheppard \\ Asia Pacific Director, HOPE International}

Development Agency, Canada/Japan

His Excellency Dr Drago Stambuk

Croatian Ambassador to Brazil, Brazil

\section{Professor Mary Stuart}

Vice-Chancellor,The University of Lincoln, UK

\section{Professor Gary Swanson}

Distinguished Journalist-in-Residence \& Mildred S.

Hansen Endowed Chair, The University of Northern Colorado, USA

\section{Professor Jiro Takai}

Secretary General of the Asian Association for Social Psychology \& Professor of Social Psychology Graduate School of Education and Human

Development, Nagoya University, Japan

Professor Svetlana Ter Minasova

President of the Faculty of Foreign Languages and

Area Studies, Lomonosov Moscow State University

\section{Professor Yozo Yokota}

Director of the Center for Human Rights Affairs, Japan Former UN Special Rapporteur on Myanmar

\section{Professor Kensaku Yoshida}

Professor of English \& Director of the Center for the Teaching of Foreign Languages in General Education, Sophia University, Tokyo, Japan 

The European Conference on Arts \& Humanities 2021

Official Conference Proceedings

ISSN: 2188-1111

(C) The International Academic Forum 2021

The International Academic Forum (IAFOR)

Sakae 1-16-26-201

Naka Ward, Nagoya, Aichi

Japan 460-ooo8

www.iafor.org 

Personal Branding on Instagram: The Challenges Encountered by Saudi Female Fitness Trainers

Wesam Basabain

pp. $1-16$

Analysing Politeness Changes When Speaking Indonesian and English: A Case Study of Indonesian-English Multilingual

Imelda Wahyuni Husein

Aceng Ruhendi Syaifullah

pp. $17-30$

A Comparative Analysis of Romeyka and Turkish Personal Experience

Narratives

Gülsüm Aydın

pp. $31-45$

The Impact of Snapchat Beautifying Filters on Beauty Standards and Selfimage: A Self-Discrepancy Approach

Rania M. Alsaggaf

pp. $47-58$

Mnemosphere: An Interdisciplinary Research between Memory of Places,

Emotions and Atmosphere of Space

Clorinda Sissi Galasso

Marta Elisa Cecchi

Ingrid Calvo Ivanovic

Ambra Borin

Claudia Mastrantoni

Martina Scagnoli

pp. $59-69$

'Climate Fiction Narratives': A Study of Maja Lunde's Novels - The

History of Bees and The End of the Ocean

Mega J Pandya

pp. $71-80$

Resilience of La Rose En Vie: Recovering from Upheaval through a Transphenomenology of Spirit on the Basis of the Arts and Humanities'

Albert Pizzaia

pp. $81-93$

The Silk Roads, 300 BCE to 1700 CE: Connecting the World for Two

Millennia

Danielle Mihram

Melissa L. Miller

pp. $95-104$

Gender differences in language about Feminism: Results from Sentiment Analysis and Use of Emojis on Twitter

Peter Bußwolder

pp. $105-118$

"Fraternal and Sisterly Love": Observing Disintegration and Resilience in The Tenant of Wildfell Hall and Shirley

Ji-Eun Kim

pp. $119-124$ 
Filipino American Identity Development in Something in Between Bussaraporn Macharoen

Supaporn Yimwilai

pp. $125-135$

Differences as a Source of Creativity: Friendship between Wang Hui and Yun Shouping

Xiao Sheng

pp. $137-143$

Disease Selects Its Victims: Inequality in Falling Ill to Infectious Disease in Bleak House

Akiko Takei

pp. $145-153$ 


\title{
Mnemosphere: An Interdisciplinary Research between Memory of Places, Emotions and Atmosphere of Space
}

\author{
Clorinda Sissi Galasso, Politecnico di Milano, Italy \\ Marta Elisa Cecchi, Politecnico di Milano, Italy \\ Ingrid Calvo Ivanovic, Politecnico di Milano, Italy \\ Ambra Borin, Politecnico di Milano, Italy \\ Claudia Mastrantoni, Politecnico di Milano, Italy \\ Martina Scagnoli, Politecnico di Milano, Italy
}

The European Conference on Arts \& Humanities 2021

Official Conference Proceedings

\begin{abstract}
The transmission of memory seems to be an obsession of our time. This issue has been addressed by different disciplines and approaches. Design, as a discipline that contributes to the enhancement of culture, can help to expand the horizon of memory studies, but so far this issue is still undefined and blurred. Mnemosphere project, through an interdisciplinary approach, investigates the ways in which the memory of places is designed and communicated through experiential spaces capable of stimulating emotions. The research proposes a dialogue between communication design and exhibition design, in the atmospheric and aesthetic dimension, with emphasis on the translation of content into a system for the understanding of the mnestic space set up. This is done with special attention to the topics of emotions, chromatic perception, and the design of temporary spaces and services. The research first considers the articulation of a common lexicon regarding the memory of places, atmospheres of spaces and atlas of emotions, among others. Then, the project analysis devices for activating the memory in exhibition spaces, through data collection and defines parameters for the design of future spaces related to memory and emotions. The result is the collective construction of an archive of visual materials for the concepts proposed. This is being done through an open call that has been spread online through the project's platforms. The shared archive and results will be available online to contribute for a further perspective on design studies connected with memory and spaces.
\end{abstract}

Keywords: Aesthetics, Memory of Places, Emotions, Exhibition Spaces, Atmosphere

\section{iafor}

The International Academic Forum

www.iafor.org 


\section{Introduction}

Mnemosphere is a research project funded by MiniFARB 2020 grant, promoted by the Design Department of Politecnico di Milano, involving Ph.D. students and research fellows coming from different academic areas. As part of the interdisciplinary dialogue within the Design field, the Mnemosphere project investigates how the memory of places can be aroused through the design of exhibition spaces in the atmospheric perspective (Böhme, 2016). The term "mnemosphere" is a neologism coined specifically by this research, conceptually expressing the themes investigated. The concepts of memory of places and atmosphere of spaces are linked by the sphere of emotions, representing the key element and conjunction of the entire research. According to Zumthor (2000), in fact, thinking about atmospheres is never separated from spatial design. Combined with fundamental elements such as light, materials, sounds, memory and reminiscences, they are part of an all-embracing design system. The "central pivot is emotion [...] and the atmosphere is constituted through the memory of places" (Alison, 2020, p. 113). The concept of mnemosphere is thus investigated aiming to find new interpretative paths within design culture, emphasizing the translation of content addressed into a system of parameters and guidelines for the design of mnestic spaces.

Mnemosphere project bases its approach on a synergic collaboration between different disciplinary fields and enriches its interdisciplinary nature with the study and analysis of emotions, colour perception, and the design of temporary spaces and services.

The research has been divided into two intermediate objectives, intended to investigate the research theme from both a theoretical and practical point of view in a different and combined way. The first one aims to establish how the different disciplines involved in the research can contribute in a specific and 'transversal' way to communicate the memory of places, starting from the existing literature and moments of comparison with the scientific community of reference. The other one is about investigating the research theme through field activities to gather data and knowledge. It is about analyzing, synthesizing, and critically interpreting the information and conducted experiences, hence defining guidelines and parameters to contribute to design culture within the memory/emotions/spaces axis.

Considering the memory of places as a lively and dynamic concept, not only rooted within the past, it is possible to expand its horizon until it enters into a design perspective. Here is why the Mnemoshere research project comprises an interdisciplinary research team with diverse backgrounds, providing a synergistic collaboration between different design fields, driven by a common goal of achieving multiple theme interpretations. Thus, the first stages of the research were focused on defining a standard glossary of reference to align the different thematic perspectives amongst the research team towards a common theoretical framework. (Fig.1) 


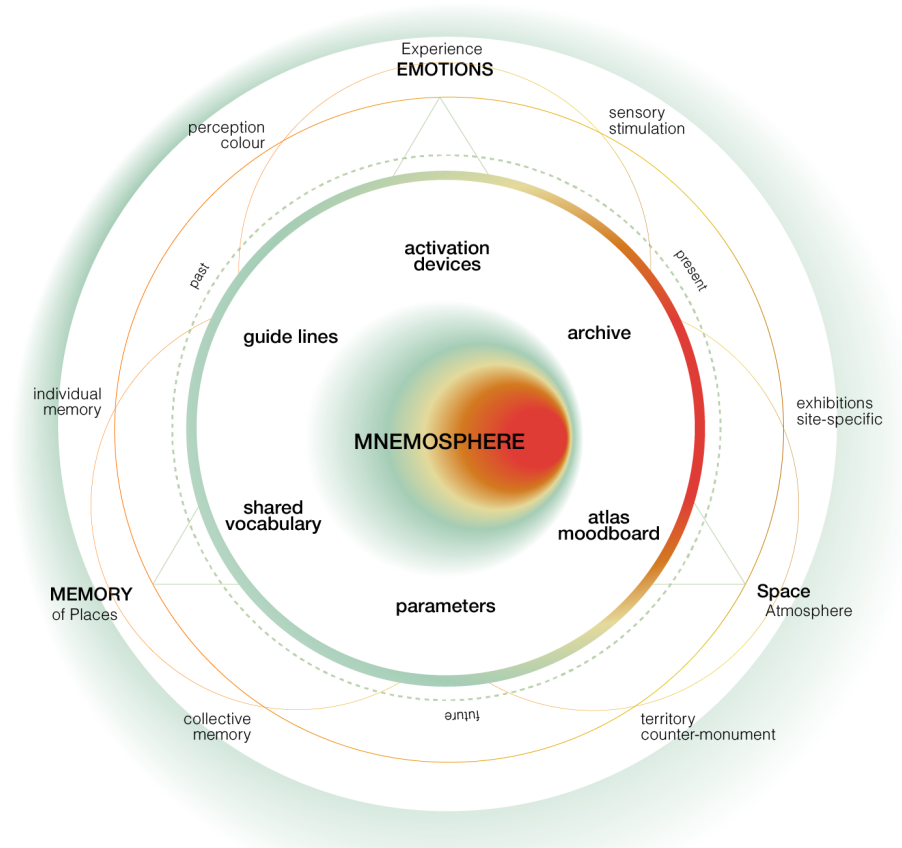

Figure 1: Mnemosphere Concept Map

The research defines that the mnemosphere context includes three main concepts: the "atmosphere of space", the "memory of places", and the "atlas of emotions". The "atmosphere of space" is defined as a temporary spatial condition between resonance and permeation, physical, cognitive and emotional, that involves the perceiving subject and the environment in a state of synchronicity; the "memory of places" as a specific site that embodies a collectively shared knowledge and, at the same time, a more private and personal form of attachment; the "atlas of emotions" as the entirety of nature and landscape of sensations, intensities and reactions related to the human lived experiences. The project intends to investigate the emerging themes by analyzing their specific communicative and visual components, by collecting data and analyzing recurring elements.

\section{Open Call for Images}

To visually explore mnemosphere topics, an Open Call for Images was launched online, spread through the project's digital platforms.

The main intention behind the process was to use a tool, the Open Call, usually connected to the art world, and apply it to a design study. It was considered preferable to use this particular format of investigation because, from the very beginning of the research, the lexical and textual apparatus appeared insufficient to define, represent and communicate the mnemosphere conceptual dimension. The visual expression of the concept, essential for its representation and perception, was missing.

The call, therefore, aimed to 'give texture' to the intangible mnemospheric concept, and was composed of a brief questionnaire and the upload of a maximum of three images for each participant. The primary part consisted of general questions on the participant's identity, like name, age, nationality. Then, the self-assessment questionnaire was structured with an inventory of questions aimed toward analyzing the potential mnemosphere dimension. The questions opened up the possibility of introducing other key concepts, describing various 
characteristics, and indicating possible synonyms. Another valuable consideration has been to offer participants the option to describe the concept through the use of antonyms. Thus, participants have been given the choice of defining intangible and elusive themes, such as those investigated in this research, through a negational and oppositional description (e.g., "the mnemosphere is not aseptic and it's not cold"; "a mnemosphere cannot be tangible"). Other questions were proposed through closed-ended answers and multiple choices, allowing participants to select several items simultaneously: like determining the mnemosphere in terms of size and movement and imagining what kind of characteristics it would have consistent from their personal point of view.

For the second part of the Open Call, the focus was entirely on the uploading of images. Each participant could submit a maximum of three files, without any restrictions in terms of format, communicative and figurative language. In fact, the images uploaded showed a wide range of formats such as photographs, illustrations, paintings, collages, drawings and sketches. The great variety of images and visual expressions made it possible to add heterogeneity and expressive variety to the research resources.

In addition, to each image uploaded, participants were asked to add the title and other information, such as the year and place of the shooting, keywords and concepts related to the image in question. Participants were also asked to express, through indicators in the form of percentages, colours and senses involved in the images. The reason behind this investigative section was to collect data on sensory approaches and synaesthetic nuances.

Lastly, a free description of the image has been included to add the right framework for each contribution (whether autonomous experiments or linked to didactic exercises etc.) and deepen each mnemosphere 'spectrum'.

The Open Call took place between mid-January and the end of March 2021, and more than 200 participants from all over the world have contributed, uploading more than 400 different images that capture the mnemospheric essence not yet explored. Once the Call was officially closed, the quality of the contributions collected was immediately evident as they were visually expressive and capable of conveying (through concepts and words) particular present and past experiences. The evocative power of the images collected enabled a first outline of different emotional landscapes, either private or collective, linked to the memory and atmosphere of the places. After collecting all the images, a multi-method approach was set up to catalogue and organize all the responses. One of these actions was to develop a website (https://www.mnemosphere.polimi.it/) as a medium to virtually configure an international 'online exhibition' of the images. A configuration that functions as a digital database that can be consulted by anyone interested in looking at the work of other participants and the various 'meanings' given to the concept of mnemosphere. In this way, users are involved in the project and thus be inspired with further interpretations.

Besides the development of the website, a careful analysis of the visual contributions submitted was followed by defining criteria, as if they were mnemospheric guidelines, through the creation of Identity Cards. 


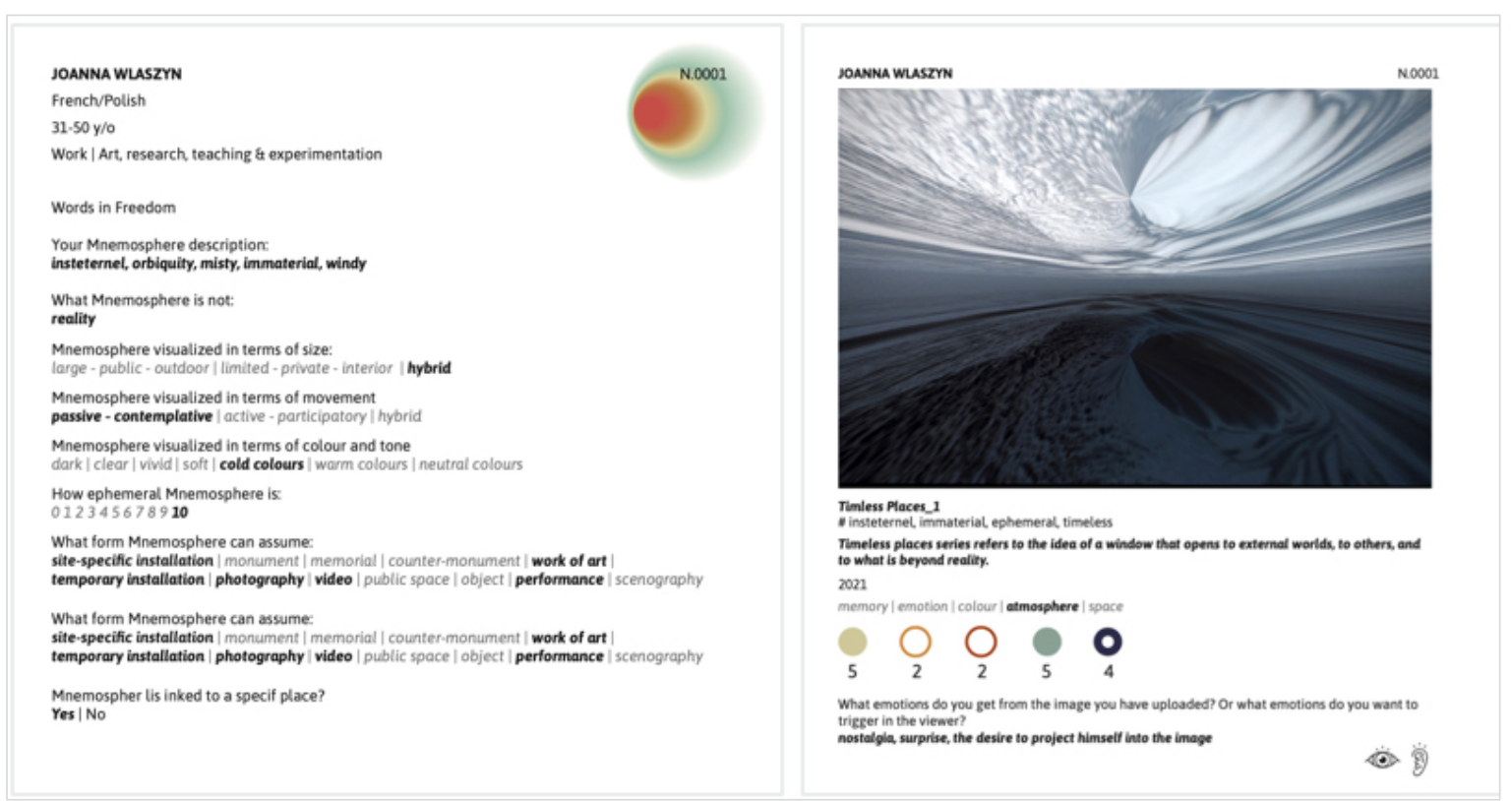

Figure 2: ID Card Example

The first step to analyze the contributions received was systematized and organized through the creation of a set of "identity cards". Data related to the general concept of mnemosphere have been discussed and processed apart. The designed identity cards have the function of summarizing all the data inherent to each image in a more effective, synthetic and visually intelligible way, thus allowing to order the contributions for analytical observation. Hence, each ID card has multiple interpretations, related to the written information (consisting of concepts and descriptions), visual information (consisting of image and color percentages) and sensory information (related to the senses involved in each image narrative).

This introductory phase sees the role of the identity cards as essential to define the relationship between the narrated and developed data. They were also refined according to the objectives and themes established at the beginning of the project, such as atmosphere, memory, space, emotion and colour.

\section{Historical Background: The Atlas}

The historical background for the images analysis takes as model the visual research of one of the most famous modern art historians, Aby Warburg. Energetic ambassador of the interdisciplinary study of culture, he pointed out, since the beginning of the 20th century, that researchers should stop policing disciplinary boundaries to gain insight into processes of cultural memory. (Erll 2008). His studies focused on what he called iconic memory (Bildgedächtnis) and materialized in his great work called the Atlas of Mnemosyne (1924-28), demonstrating how certain "pathos formulae" migrated through different artworks, periods, and countries (Erll 2008). Mnemosphere workshop process was inspired by his panel system, a practice of assembling and organizing images that made it possible to perceive at a glance, the nuclei of visual and mnestic investigation, placed not in hierarchical relation to each other and continuously modifiable according to the evolution of research (Forster and Mazzucco 2002). These iconographic schemes were useful to connect artworks, artists, creative inspirations, and suggestions that converged into proper tables, panels that could be exhibited and be part of various forms of installations. At the beginning of Warburg's research, the tables 
were meant to be only the introduction of the project, but soon became the core of the work which was dedicated to the Greek goddess protector of memory and remembrance.

In Warburg Atlas, which contains about one thousand photographs assembled and arranged following a new academic method of looking, the images are the subject of privileged study because they provide a direct way of narrating cultures, histories and aesthetics of the world. The image is the locus in which impression and memory come together and condense. Endowed with primordial energy and powers of evocation on the strength of their expressive vitality, images are the principal vehicles and supports of the cultural tradition and social memory, which in certain situations can be "reactivated and downloaded" (Iuav, 2012). In the Atlas, the juxtaposition of images, that weave several themes around a core element, creates energy fields and triggers in the beholder an open interpretative process: "the word to the image". The importance of Warburg's work lies in the evocative power of panels that are not trapped in linear and ordered sequences but develop in fluid and continuously updatable assemblages. His translating operation allows new paths of meaning and emotion to be discerned in historical and pre-existing materials thanks to a carefully designed juxtaposition. Mnemosyne Atlas is an interpretative machine, a kind of enormous condenser, in which all the energy currents that animate and enhance cultural and communicative memory are collected.

The mnemospheric experimentation, which took shape in the open call, wants to offer a series of visual hypertexts, in which the images will lose part of their initial meaning to acquire others suitable for the recognition of the atmospheres and the memory of places. It will not be a sterile loss, but functional to the development of the collective mnemosphere definition. Inspired by Warburg, the Mnemosphere Atlas aims to be an activator of the memory of places, a tool and an apparatus to navigate in the context of atmosphere, memory, colours, and emotions.

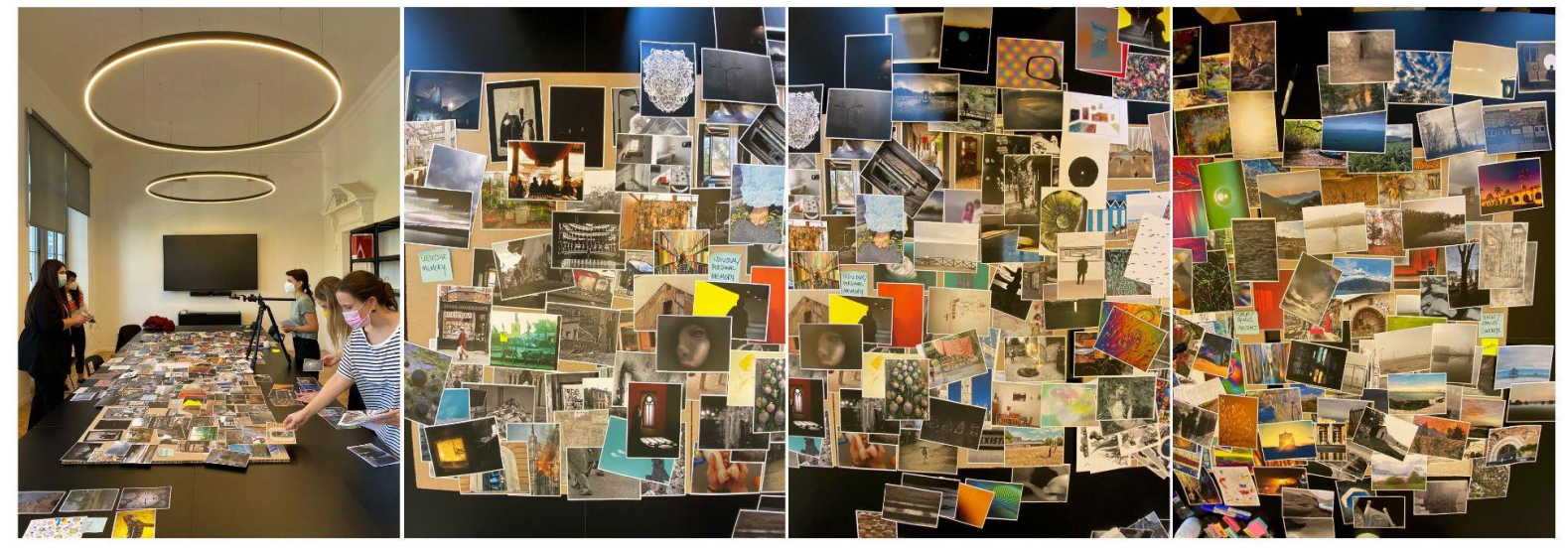



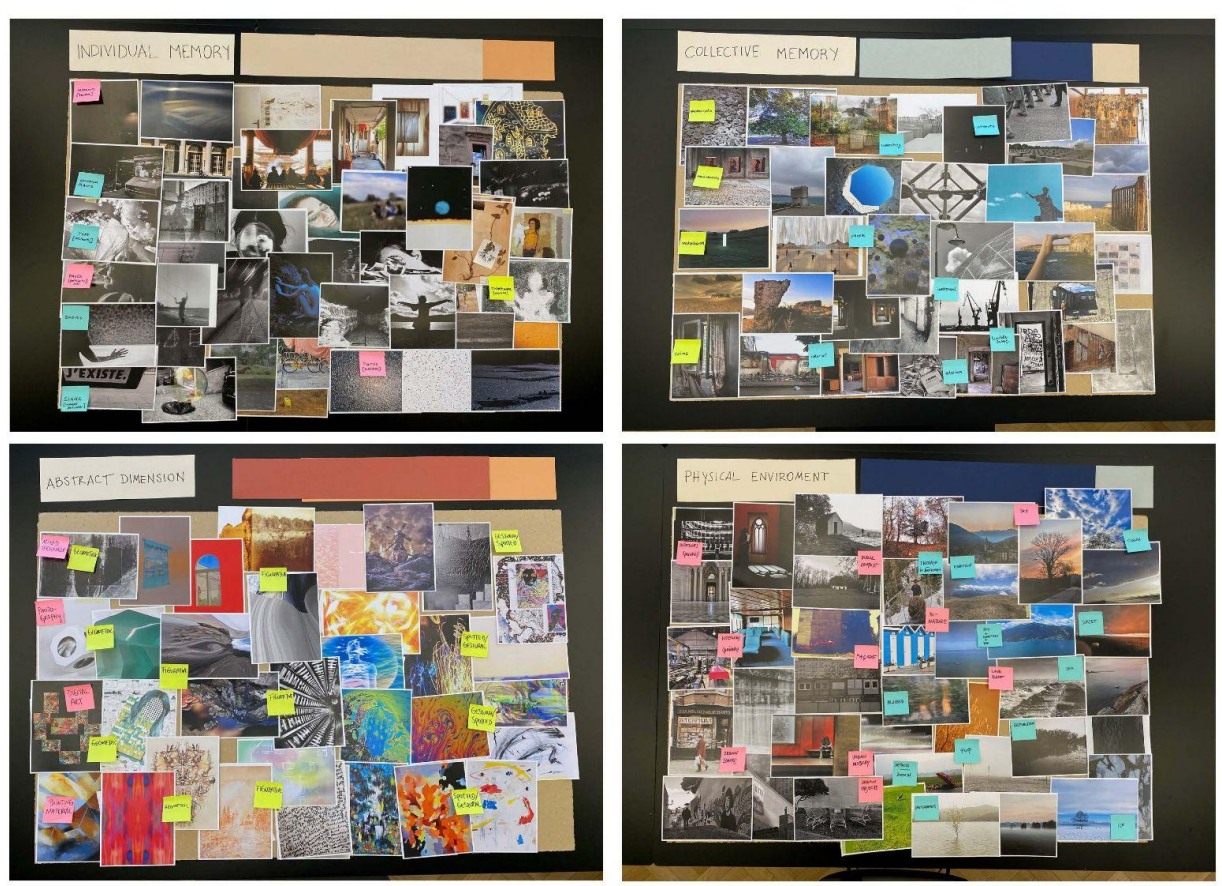

Figure 3: Internal Workshop Process and Tables

\section{Results and Discussion}

After the Open Call for Images, the research actions were dedicated to recognizing common red threads and recurring elements running through the collected images that can be translated into parameters. All the atlases are different from each other. This aspect highlights how the analysis of images and texts can follow different directions depending on how the concepts are to be conceived.

Therefore, each atlas is considered a dynamic, ephemeral, and active tool as it can constantly change. Hence, these atlases reflect the inner nature of the topics addressed, which are unlikely to be precisely contained and defined in one unified way.

During the first workshop within the research group, the images were initially organized and arranged according to the atmospheric perspective related to spaces and places, considering also the descriptions and concepts given by the call participants. The clusters inherent to this section were set up in advance as reference macro-categories: "air", "bubble", "diaphragm", "haze", "colorful", "nets" and "void". Subsequently, within each macro-area, more defined clusters of images were identified, acting as thematic sub-categories. Then, this information was translated into more precise spatial conformations and morphological elements, identifying the main features of each atlas (Figure 4).

The recurring themes emerging from these atlases are, for example, natural landscapes, portraits and period photographs, architecture, ruins, blurred atmospheres, and abstract visualizations. 


\begin{tabular}{|c|c|c|}
\hline $\begin{array}{l}\text { Main } \\
\text { Clusters }\end{array}$ & Related Sub-categories & $\begin{array}{l}\text { Spatial Conformations and Morphological } \\
\text { Elements }\end{array}$ \\
\hline AIR & $\begin{array}{l}\text { air, wind, aperture, sky, flight, } \\
\text { vastness, horizon, wingspan }\end{array}$ & $\begin{array}{l}\text { openness, no borders, big long shots, } \\
\text { low-angle shots, glance beyond }\end{array}$ \\
\hline BUBBLE & $\begin{array}{l}\text { focus, eyes, dimensions, } \\
\text { habitat, fullness, closure }\end{array}$ & $\begin{array}{l}\text { roundness, bubbles, nests, spheres, clear } \\
\text { outlines inside out, focal point, light focus }\end{array}$ \\
\hline DIAPHRAGM & $\begin{array}{l}\text { filters, thresholds, constructs, } \\
\text { entrances, views, portals }\end{array}$ & $\begin{array}{l}\text { movement, sequences, linear paths, holes, } \\
\text { cuts, passages, upturned reflections, over \& } \\
\text { below }\end{array}$ \\
\hline HAZE & $\begin{array}{l}\text { fog, overlaps, accelerations, } \\
\text { faded, limitless, muffled, } \\
\text { chaos }\end{array}$ & $\begin{array}{l}\text { transparencies, opacity, blurred, out of } \\
\text { focus, diffuse, dazzling, in motion, blended }\end{array}$ \\
\hline COLOURFUL & $\begin{array}{l}\text { chromatic, rhythms, textures, } \\
\text { vibration, rainbows, spectrum }\end{array}$ & $\begin{array}{l}\text { tones, brightness, blends, accents, } \\
\text { shadows, intensity, contrast, harmony, } \\
\text { iridescence }\end{array}$ \\
\hline NETS & $\begin{array}{l}\text { webs, connections, contact, } \\
\text { mutation, growth, systems }\end{array}$ & $\begin{array}{l}\text { organic, natural, interconnected, interlaces, } \\
\text { nucleus, bonds, complexity }\end{array}$ \\
\hline VOID & $\begin{array}{l}\text { lack, loneliness, instants, } \\
\text { nothing, ruins, silence }\end{array}$ & $\begin{array}{l}\text { old portraits, industrial abandoned places, } \\
\text { no-places, close-ups and zoom-in, textures }\end{array}$ \\
\hline
\end{tabular}

Figure 4: Definition of the First Seven Visual Atlases Regarding the Concept of Atmosphere

The internal workshop organised afterwards continued with the arrangement of the atlases, this time from the perspective of memory. Four additional thematic clusters were obtained, which arose spontaneously mainly during the textual analysis of the descriptions given by the participants, and subsequently the visual analysis of the images was performed.

The thematic clusters refer to the following concepts within which additional subclusters and red threads could be identified as follow:

- $\quad$ "individual memory", in which people's faces, bodies, animals, portraits, frozen moments and instants, signs, and symbols of different kinds mainly appear;

- $\quad$ "collective memory", consisting of memorials, monuments, ruins, cemeteries and landmarks;

- $\quad$ "physical environment", linked to pictures of anonymous places charged with their narrative, wild natural landscapes, generic urban contexts, and domestic or private interiors;

- $\quad$ "abstract dimension", i.e. images constructed using different artistic techniques, characterized by vivid and saturated colours aimed at emphasizing the emotional impact of external places through internal emotional tones only.

Hence, two different approaches were used to structure the atmosphere-based and memorybased atlases, stressing two conceptual approaches that analyse the topic of "mnemosphere" from parallel perspectives but drawing from the same sources.

An overview of some of the atmospheric-based and memory-based atlases can be seen in Figure 5 . 


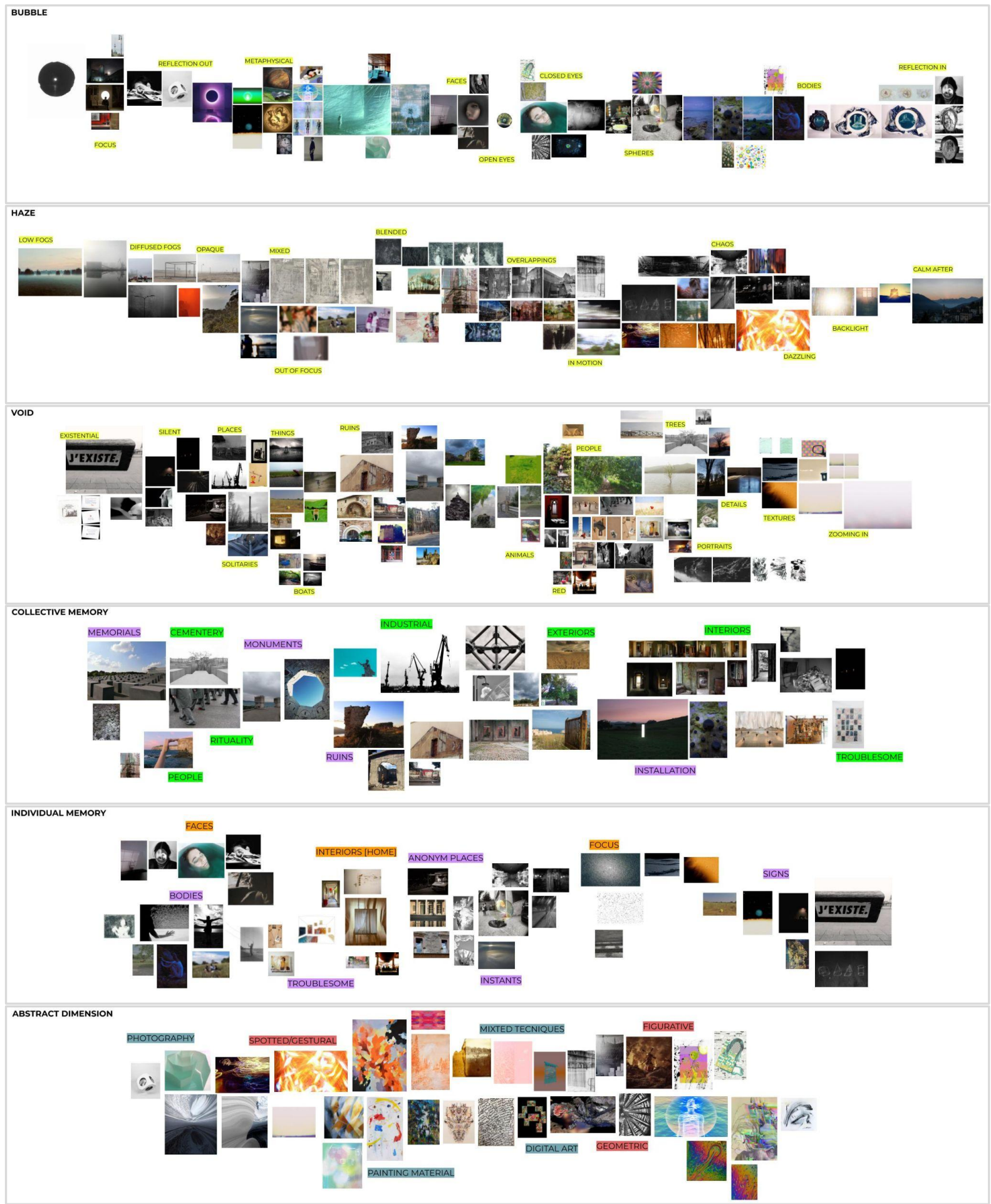

Figure 5: The First Examples Illustrate the Atmosphere-based Atlases of "Bubble", "Haze", and "Void", While the Following Three Examples Represent the Memory-based Atlases of "Individual Memory", "Collective Memory" and "Abstract-Dimension".

\section{Conclusion}

The results obtained reveal the complex nature of memory rooted in places, and how emotions are involved in its atmospheric communication and expression. 
The subdivision into categories of the images is not intended to define precisely the areas investigated but rather to provide an orientational framework through the arrangement of the various contents.

In parallel with the analysis of the images, the colour component was also investigated, as it represents one of the main axes of this research. The chromatic analysis led to the definition of specific chromatic codes for each thematic cluster.

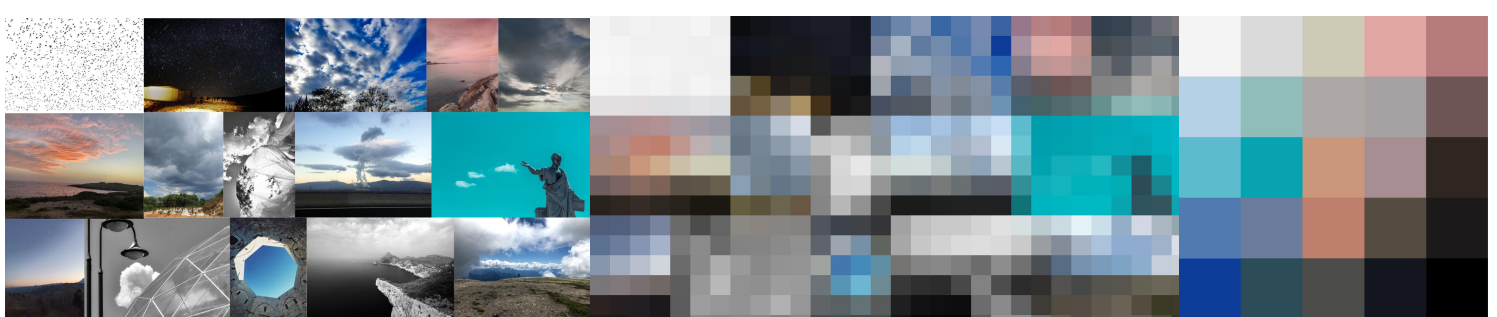

Figure 6: Colour Analysis Example to Obtain Specific Chromatic Codes for Each Atlas

It evaluated the different shades and saturation of the colours concerning the themes investigated. The resulting identification of visual communication guidelines from a chromatic point of view is complementary to the definition of parameters and guidelines for the design of exhibition spaces capable of evoking the memory of places.

Hence, the current state of research is still in the process of analysis to determine parameters and guidelines for the design of spaces, which is one of the main objectives of this research.

The focus of the project is to define the concept of mnemosphere through a collective and participatory mode and visualize its mutable manifestations through interactive and dynamic atlases to be collected in an open-access publication. Furthermore, Mnemosphere's interactive and digital atlases trace remembrance, spaces and sites through changing and temporary images, in which paradoxically the purpose is to "turn an ephemeral message into a permanent memory" (Tumminelli, 1997).

The final aim is to inspire further original reflections, by addressing researchers and scholars fascinated by the mnemospheric world. The Mnemosphere Atlas can also facilitate and enhance the dialogue between design and other disciplines, bringing together different voices and perspectives. 


\section{References}

Alison, A. (2020). Atmospheres and Environments: Prolegomena to Inhabiting Sensitively. Aesthetica Preprint (Mimesis), 15, 97-121. https://doi.org/10.7413/0393-8522050

Böhme, G. (2016). The Aesthetics of Atmospheres (J.-P. Thibaud (ed.); 1st ed.). Routledge.

Erll, A. \& Nünning, A. (2008). Cultural Memory Studies. Berlin, New York: De Gruyter.

Forster, K. , \& Mazzucco, K. , \& Centanni, M. (2002). Introduzione ad Aby Warburg e all'Atlante della Memoria. Milano: Bruno Mondadori.

Iuav, Centro Studi. (2012). Mnemosyne Atlas. La Rivista Di Engramma.

http://www.engramma.it/eOS/core/frontend/eos_atlas_index.php?id_articolo=4089\#

Tumminelli, P. (1997). Designing the ephemeral. Domus Dossier, april(5), 4-6.

Warburg, A. , \& Ohrt, R. Heil, A. (2020). Bilderatlas Mnemosyne: the original. Berlin: Hatje Cantz.

Zumthor, P. (2000). Atmospheres: Architectural Environments - Surrounding Objects (1st ed.). Birkhäuser Architecture.

Contact email: clorindasissi.galasso@polimi.it 
(C) The International Academic Forum 2021 The International Academic Forum (IAFOR)

Sakae |-|6-26-20|

Naka Ward, Nagoya, Aichi

Japan 460-0008

www.iafor.org 